
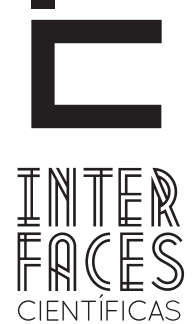

DIREITO

\title{
A PRESCRIÇÃO DA PRETENSÃO DE REPARAÇ̃̃O POR RESPONSABILIDADE CONTRATUAL DECORRENTE DE RELAÇÃO DE CONSUMO: UM DIÁLOGO ENTRE O CÓDIGO CIVIL E 0 CÓDIGO DE DEFESA DO CONSUMIDOR
}

Fernando Gaburri ${ }^{1}$

\section{RESUMO}

0 presente artigo é uma breve síntese da aula ministrada na manhã do dia 04.05.2013, na turma de pós-graduação em Direito civil e processual civil da Universidade Tiradentes (UNIT), a cujos alunos dedico essa breve reflexão. A proposta do texto é analisar a prescrição da pretensão ressarcitória decorrente de inadimplemento contratual de operadora de plano de saúde que se negou a cobrir cirurgia de implantação de stent em paciente segurado. A discussão principal gira em torno da identificação do prazo prescricional aplicável, afastando-se, desde logo aquele previsto no art. 27 do Código de Defesa do Consumidor (CDC), o qual trata de responsabilidade extracontratual. 0 ju- ízo da $3^{a}$ Vara Cível de Porto Alegre e o Tribunal de Justiça do Rio Grande do Sul entendeu pela aplicação do prazo trienal do art. 206, § $3^{\circ}$ do Código Civil (CC), ao passo que o Superior Tribunal de Justiça reiterou seu entendimento, no sentido de ser o prazo geral decenal do art. 205 do CC o aplicável na espécie. Outro ponto de relevo no julgado, e abordado no presente estudo, é o da aplicação, ou não, da regra de direito intertemporal do art. 2.028 do CC.

\section{PALAVRAS-CHAVE}

Direito Civil. Prescrição. Responsabilidade Contratual. 


\section{ABSTRACT}

This article is a brief summary of the lecture delivered on the morning of May 4, 2013 in the class graduate in civil law and civil procedure at the University Tiradentes (UNIT), whose students I dedicate this brief reflection. The proposed of the paper is to analyze the prescription of compensatory claims arising from breach of contract carrier's health plan refused to cover surgery sent in a patient insured. The main discussion revolves around the identification of the applicable statute of limitations, moving away from that provided for in art. 27 of the Consumer Defense Code $(C D C)$, which comes to non-contractual liability. The judgment of the 3rd Civil Court of Porto Alegre and the Court of Rio Grande do Sul, understood by the application of the three-year term of art. 206, § 3 of the Civil Code (CC), while the Superior Court of Justice reiterated his understanding in the sense of being the general term decadal term of art. 205 of the Civil Code in the applicable on the species. Another important point in the judged and addressed in this study is the application, or not, of intertemporal law rule of art. 2.028 of CC.

\section{KEYWORDS}

Civil Law. Prescription. Contractual Liability.

\section{RESUMEN}

Este artículo es un breve resumen de la Conferencia dictada en la mañana del 04.05.2013 en la clase de posgrado en derecho civil y procesal civil de la Universidade Tiradentes - UNIT, a cuyos alumnos dedico esta breve reflexión. El propuesto es analizar la prescripción de las pretensiones reparatorias en consecuencia de incumplimiento contractual de una operadora de plan de salud que se negó a cubrir la cirugía para implantación de stent en un paciente asegurado. La discusión gira en torno a la identificación del plazo de prescripción aplicable, descartándose desde ya el plazo dispuesto en el art. 27 del Código de Defensa del Consumidor - CDC, que se refiere a responsabilidad extracontractual. La sentencia de la tercera Vara Civil de Porto Alegre y la Corte del Río Grande do Sul, optaron por el uso del plazo de tres años del art. 206, párrafo 3 del Código Civil-CC, mientras que el Tribunal Superior de Justicia reiteró su comprensión al plazo general decenal del art. 205 del Código Civil aplicable en la especie. Otro importante punto en el juicio y enfocado en este estudio es la aplicación, o no, de la regla de derecho intertemporal del art. 2.028, CC.

\section{PALABRAS CLAVE}

Derecho Civil. Prescripción. Responsabilidad Contractual.

\section{TEMPO COMO FATO JURÍDICO}

A prescrição reflete a influência do tempo - fato jurídico - nas relações jurídicas.

Muito se discute sobre os fundamentos da prescrição, havendo quem o repute até imoral. Em lições de direito romano, proclama José Cretela Júnior (1998) que, em um contrato, o devedor, cuja exigibilidade da dívida fora atingida pela prescrição, fica liberado /ure civili, mas ainda se obriga iure naturali. Daí dispor o art. 882 do CC que aquele que solve obrigação cuja pretensão está prescrita não tem direito de reclamar a restituição do que pagou.

Conforme sintetiza Orlando Gomes (1998), alguns justificam a prescrição como sanção à negligência do titular do direito, de modo que sua inércia torna- 
ria presumível o desinteresse. Outros a explicam por motivos de ordem social, já que seria a segurança do comércio jurídico que exige a consolidação das situações jurídicas pelo decurso de tempo. Isto porque se trata de medida de política jurídica, ditada no interesse da harmonia social.

\section{DIREITO SUBJETIVO E DIREITO POTESTATIVO}

O ponto primordial para o estudo da prescrição e da decadência é a distinção entre direito subjetivo e direito potestativo.

O prazo de prescrição é o lapso de tempo dentro do qual pode ser exercido um direito subjetivo, a contar de quando foi violado, pois é neste momento que nasce a pretensão. Já no tocante à decadência, não há que se falar em violação: nascido um direito potestativo, juntamente com ele surge um prazo dentro do qual deve ser exercido.

O direito a uma prestação ou direito subjetivo, conforme Francisco Amaral (2005) pressupõe o poder de um sujeito exigir do outro um comportamento consistente em dar, fazer ou não fazer. 0 devedor, mediante uma dessas formas de prestação, deve colaborar para a concretização do direito do credor.

Caso o devedor não adimpla a prestação no prazo avençado, ou quando ocorrer a condição a cujos efeitos o negócio estava subordinado, haverá a violação do direito subjetivo do credor. Uma vez violado esse direito, nasce para o credor a pretensão, ou seja, a possibilidade de exigir o adimplemento forçado daquela prestação.

É possível perceber que o direito subjetivo é um direito pronto, já formado, e, por isso, passível de ser exigido.
Mais adiante, o citado autor observa que a prescrição se funda no interesse social da segurança do comércio jurídico, daí ser incontestável sua natureza de instituto de ordem pública.

Já diante dos chamados direitos potestativos, seu titular não possui pretensão junto à outra parte. Seu direito consiste apenas na possibilidade de constituir, desconstituir ou modificar uma relação jurídica já existente, o que não pressupõe a colaboração do devedor.

Segundo Francisco Amaral (2005), direito potestativo é o poder que o agente tem de interferir na esfera jurídica de outrem, constituindo, modificando ou extinguindo uma situação subjetiva, sem que esta possa fazer alguma coisa senão sujeitar-se. Cabe ao titular da situação de sujeição, apenas conformar-se com a vontade do titular do direito potestativo.

Se o direito potestativo tiver prazo para o seu exercício, este prazo será decadencial, sempre.

Com base na distinção entre direito subjetivo e direito potestativo, Orlando Gomes (1998), com extrema lucidez, há muito noticiava que um interessante critério para se identificar qual prazo é prescricional, e qual é decadencial, seria o da classificação das ações pela eficácia da sentença que suscitam. E assevera que estariam sujeitas à prescrição as ações condenatórias e à decadência, as ações constitutivas. E justifica que essa distinção toma por base a estrutura do direito atingido pelo decurso de tempo. Assim, os direitos providos de pretensão seriam prescritíveis, eis que o exercício da pretensão por meio de ação judicial visa à obtenção de sentença condenatória. Já os di- 
reitos desprovidos de pretensão, os chamados direitos potestativos, se necessário seu exercício por meio de ação judicial, demandam sentença constitutiva.

Como observa Fábio Konder Comparato, direito subjetivo e pretensão não se confundem, pois aquele é a pertinência de um bem da vida a alguém, e a pretensão é o modo, judicial ou extrajudicial, reconhecido pelo ordenamento jurídico para garantir o respeito ao direito subjetivo (2010).

No tocante aos negócios nulos, descabe falar em decadência, pois, conforme ensina Emilio Betti (2003), se é certo que existe um direito à anulação, inexiste um particular direito à nulidade do negócio. Isso porque - arremata o autor italiano - depois de celebrado um negócio absolutamente nulo, continua a subsistir a situação jurídica já existente, que somente se alteraria se o negócio fosse válido.

\section{ORGANIZAÇÃO DOS PRAZOS PRESCRICIONAIS NO CÓDIGO CIVIL}

Além da adoção de um critério científico para distinguir os prazos prescricionais e decadenciais, o CC/02, visando atender ao princípio da operabilidade (neste caso entendido como simplicidade), procurou tratar didaticamente a matéria, preceituando que os prazos prescricionais são apenas os dos arts. 205 e 206 , de modo que todos os demais previstos ao longo do CC, seja em sua parte geral, seja na especial, seriam decadenciais.

\subsection{INÍCIO DA CONTAGEM}

Como a prescrição implica na perda da pretensão, a contagem do prazo prescricional inicia-se no momento em que aquela pretensão nasce, pois actioni nondum natae non praescribitur.
Quanto às ações de natureza declarativa, que visam apenas à certificação de existência ou inexistência de uma relação jurídica, ou a autenticidade ou falsidade de um documento (CPC, art. $4^{\circ}$ ), não há que se falar em prescrição ou decadência. Neste caso não se discute direito violado nem relação a ser constituída ou desconstituída.

Operada a prescrição, não se pode falar em extinção do direito subjetivo do credor. Ocorre, no entanto, que o credor fica sem mecanismo jurídico para exigir a prestação do devedor. Mas, se o devedor quiser adimplir sua prestação, ainda que juridicamente inexigível, não poderá depois reclamar repetição - restituição - do que pagou, pois, posto que inexigível juridicamente, a prestação ainda era devida (CC, art. 882). E ao tornar-se obrigação juridicamente inexigível, seu adimplemento fica condicionado ao querer do devedor. Caso este a adimpla terá renunciado à prescrição, que já operara em seu favor.

Insta salientar que não só no CC existem prazos prescricionais. 0 que se quer dizer é que o CC os condensou em seus arts. 205 (prazo prescricional residual geral de 10 anos) e 206 (prazos especiais de 1 a 5 anos). Outras leis, a exemplo do CDC, trazem em seu texto outros prazos prescricionais. 
Se a obrigação for positiva (dar ou fazer) a pretensão nasce no momento em que o devedor incorre em mora, ou seja, no vencimento da obrigação não dá, ou não faz, o que se obrigara.

Por outro lado, nas obrigações negativas (de não fazer) o devedor incorre em mora quando faz aquilo a que se obrigara a abster e, por conseguinte, é neste momento em que o direito é violado e que começa a correr o prazo de prescrição da pretensão.

Se a obrigação contiver em si algum fator eficacial, este deverá ser observado para o início da contagem do prazo prescricional. Assim, nas obrigações sob condição, é o advento do evento futuro e incerto que fixará o início da contagem; nas obrigações a termo é a chegada do evento futuro e certo que fará essa contagem iniciar-se.

Nos direitos reais, a contagem do prazo prescricional segue a regra das obrigações negativas. Se os direitos reais têm oponibilidade erga omnis, é fácil concluir que fazem surgir um dever geral e negativo consistente em que ninguém pode molestar o exercício do direito de seu titular. A partir do momento que alguém faz o que, por lei, estava obrigado a não fazer, acaba por violar direito alheio, o que faz nascer, a partir de então, a pretensão.

Entretanto, o problema é bem mais complexo, porquanto existem casos em que a pretensão surge pos-

\subsection{A VIOLAÇ̃̃O CONTRATUAL EM RELAÇ̃̃O DE CONSUMO}

De início, devem-se frisar as principais distinções entre responsabilidade civil contratual e extracontratual, pois o dever de indenizar pode ter como fonte, ou fato gerador, o inadimplemento de uma obrigação negocial, ou então a lesão de um direito subjetivo. Deste modo, diz-se que, quanto ao seu fato gerador, teriormente à violação, de modo que a lesão não pode sofrer resistência no momento de sua perpetração, em razão do que não pode começar a correr o prazo prescricional.

Nesta linha, a doutrina e a jurisprudência atuais vêm adotando a antiga tese da actio nata, expressamente contemplada no art. 27 do CDC, para a qual o início do decurso de um prazo prescricional ocorre a partir de quando o prejudicado toma conhecimento do fato danoso. Esse princípio é adotado em sede de responsabilidade civil, tanto em relação ao CC como ao CDC. Assim, a pessoa que, por exemplo, for vítima de um erro médico, terá o prazo prescricional para reclamar reparação civil contado não do momento em que o dano foi perpetrado, mas da data do conhecimento do fato danoso. A este respeito decidiu o STJ recentemente:

DIREITO PROCESSUAL CIVIL. AÇÃO DE COBRANÇA DE SEGURO OBRIGATÓRIO. PRESCRIÇÃO. TERMO INICIAL. CIÊNCIA INEQUÍVOCA DA INCAPACIDADE. REEXAME DE FATOS E PROVAS. INADMISSIBILIDADE.

- A ação de cobrança de seguro obrigatório (DPVAT) prescreve em três anos, contados da data em que o segurado toma ciência inequívoca da incapacidade.

- $\quad$ O reexame de fatos e provas em recurso especial é inadmissível.

- $\quad$ Agravo não provido. (STJ - $3^{a}$ t. AgRg no REsp. 1.181.902/MT

- $\quad$ Rel. Min. Nancy Andrighi - j. em 16.08.2011 - v. u.).

a responsabilidade civil pode ser contratual e extracontratual.

No primeiro caso, como preexiste uma relação jurídica entre autor do dano e vítima, diz-se que a responsabilidade é contratual; e no segundo caso, como 
inexistia, até o momento do dano, nenhuma relação jurídica entre seu autor e a vítima, diz-se que a responsabilidade é extracontratual (GABURRI, 2012).

Álvaro Villaça Azevedo (2004) explica que, se "A" e " $B$ " concluem um contrato para regerem determinada relação jurídica entre ambos, esse contrato faz lei entre eles. 0 descumprimento de qualquer cláusula daquele contrato ensejará para o inadimplente uma responsabilidade, de cunho contratual. Já aquele que descumpre a norma legal de não lesar a ninguém - neminem laedere - acarreta ao transgressor, responsabilidade extracontratual, pois aqui, o que se descumpriu não foi um contrato, mas uma lei.

Salienta Vincenzo Franceschelli (2007) que pode suceder que um mesmo evento constitua inadimplemento contratual e ilícito civil, caso em que haverá um concurso entre responsabilidade contratual e extracontratual. 0 prejudicado poderá então intentar demanda com base em uma ou em outra. Logicamente que, se optar pela responsabilidade extracontratual, deverá, via de regra (ou seja, nas relações regidas pelo (C), provar a culpa do agente causador do dano; já, se optar pela responsabilidade contratual, deverá provar apenas a existência do título e de seu inadimplemento.

Essa distinção é relevante para casos como o analisado, pois se o paciente, além de ter arcado com os custos do tratamento, tivesse sofrido danos a sua saúde, estes decorreriam de infração ao dever de não lesar a ninguém (neminem laedere), cuja natureza jurídica seria de responsabilidade extracontratual.

Lembra Jean Carbonier (1956) que na responsabilidade contratual com pluralidade de devedores não há presunção de solidariedade, conforme resulta expresso do art. 265 do CC, ao passo que, se a ofensa delitual (extracontratual) tiver mais de um autor, todos são considerados solidariamente responsáveis, nos termos da $2^{a}$ parte do art. 942 do CC.
Essas distinções podem ser sintetizadas conforme esquema a seguir:

\begin{tabular}{|c|c|c|}
\hline & $\begin{array}{l}\text { Responsabilida- } \\
\text { de contratual }\end{array}$ & $\begin{array}{l}\text { Responsabilidade } \\
\text { extracontratual }\end{array}$ \\
\hline $\begin{array}{l}\text { Relação } \\
\text { jurídica: }\end{array}$ & $\begin{array}{l}\text { Preexiste uma } \\
\text { relação jurídica } \\
\text { entre credor e de- } \\
\text { vedor. }\end{array}$ & $\begin{array}{l}\text { Inexiste prévia re- } \\
\text { lação jurídica, ha- } \\
\text { vendo violação do } \\
\text { dever de não lesar } \\
\text { a ninguém. }\end{array}$ \\
\hline $\begin{array}{l}\text { Ônus da } \\
\text { prova: }\end{array}$ & $\begin{array}{l}\text { O prejudicado } \\
\text { deve provar ape- } \\
\text { nas a existência } \\
\text { da relação ju- } \\
\text { rídica e de seu } \\
\text { inadimplemento. }\end{array}$ & $\begin{array}{l}\text { Em regra, o ofen- } \\
\text { dido deve provar } \\
\text { a conduta culposa } \\
\text { do agente, e que } \\
\text { desta conduta re- } \\
\text { sultou o dano. }\end{array}$ \\
\hline $\begin{array}{l}\text { Cláusula } \\
\text { de não } \\
\text { indenizar: }\end{array}$ & $\begin{array}{l}\text { Admite cláusula } \\
\text { de exclusão, ou } \\
\text { de redução, da } \\
\text { indenização. }\end{array}$ & $\begin{array}{l}\text { Não admite tal } \\
\text { cláusula. }\end{array}$ \\
\hline
\end{tabular}

Passadas em análise os principais pontos distintivos entre a responsabilidade civil contratual e extracontratual, cabe agora enfrentar a tarefa de identificar, no caso em estudo, o prazo prescricional a ser observado para o exercício da pretensão ressarcitória do paciente que teve a cobertura do tratamento negada pelo plano de saúde.

O CC traz um prazo geral de prescrição de 10 anos em seu art. 205, para o caso de a hipótese fática não se subsumir a nenhum dos dispositivos de seu art. 206.

Já o CDC traz um único prazo prescricional, de 5 anos, em seu art. 27, aplicável à pretensão de reparação de danos causados por fato do produto ou fato do serviço (acidente de consumo). 
0 art. 27 do CDC, portanto, refere-se tão somente à pretensão reparatória decorrente de responsabilidade civil extracontratual. No caso de violação de contrato o prazo prescricional deverá ser buscado em outro dispositivo, de outro diploma jurídico, já que o CDC só dispõe sobre prescrição em seu art. 27.

No caso de responsabilidade contratual em relação de consumo o prazo não será o quinquenal do art. 27 do CDC, mas o geral do art. 205 do CC. inaplicável à responsabilidade contratual do fornecedor.

Neste sentido decidiu o STJ:

RECURSO ESPECIAL. PLANO DE SAÚDE. AÇÃO DE RESSARCIMENTO. CIRURGIA CARDÍACA. DESCUMPRIMENTO DE CLÁUSULA CONTRATUAL. PRAZO PRESCRICIONAL DECENAL.

1. Em se tratando de ação objetivando o ressarcimento de despesas realizadas com cirurgia cardíaca para a implantação de "stent", em razão da negativa do plano de saúde em autorizar o procedimento, a relação controvertida é de natureza contratual.

2. Não havendo previsão específica quanto ao prazo prescricional, incide o prazo geral de

\subsection{A REGRA DE TRANSIÇÃO DO ART. 2.028 DO CÓDIGO CIVIL}

A ementa do REsp. 1.176.320/RS faz referência à regra de transição do art. 2.028. do CC, que será objeto de análise neste tópico.

Embora na íntegra da Apelação Cível n. 70027224112, apreciada pela $6^{\text {a }}$ Câmara Cível do Tribunal de Justiça do Rio Grande do Sul, sob a relatoria do Desembargador Luís Augusto Coelho Braga, com data de Julgamento em 10.09.2009, não conste a data da negativa do plano de saúde de autorização do procedimento cirúrgico, acredita-se ter sido antes da vigência do $C C / 02$. Se assim não fosse, não haveria sentido para invocação do art. 2.028 do CC, que traz regra de direito intertemporal.
10 (dez) anos, previsto no art. 205 do Código Civil, o qual começa a fluir a partir da data de sua vigência (11.1.2003), respeitada a regra de transição prevista no art. 2.028.3.- Recurso Especial provido." (STJ - $3^{a}$ t. - REsp. 1.176.320/RS - Rel. Min. SIDNEI BENETI - j. em 19.02.2013 - v. u.).

No caso em espécie, o autor (recorrente) ajuizou ação buscando o ressarcimento das despesas realizadas com cirurgia cardíaca para implantação de stent, no valor de $\mathrm{R} \$ 6.365,66$, devido à negativa do plano de saúde Golden Cross em cobrir o procedimento. 0 Tribunal de Justiça do Rio Grande do Sul julgara improcedente a pretensão autoral, aplicando o art. 206, $\S 3^{\circ}, \mathrm{V}$, do CC, que prevê o prazo prescricional de 3 anos para o exercício da pretensão de reparação por ato ilícito.

Em seu voto, o Ministro Relator ressaltou que a hipótese não se subsume ao prazo de 1 ano do art. 206, $\S 1^{\circ}, \mathrm{II}$, do CC, porque a causa de pedir da pretensão não decorre de contrato de seguro, mas da prestação de serviço de saúde, que recebe tratamento próprio.

Atendendo aos anseios da coletividade, e em consonância com as atuais facilidades de comunicação e de deslocamento, no entanto, com a entrada em vigência do CC/02 podem ser constatados três tipos de situações, no tocante ao decurso do tempo:

a) situação pretérita, em que o prazo decadencial ou prescricional iniciou-se e concluiu-se durante a vigência da lei anterior;

b) situação futura, em que o prazo decadencial ou prescricional começou a fluir a partir da vigência do $\mathrm{CC} / 02$; e 
c) situações pendentes, em que o prazo decadencial ou prescricional começou a fluir na vigência da lei anterior e ainda não se escoou completamente quando da entrada em vigência do $\mathrm{CC} / 02$.

É esta última situação - pendente - que ora interessa de perto.

No entanto, antes de se proceder em sua análise, é importante que o estudioso se recorde do princípio da irretroatividade das leis, estudado no capítulo 2 deste volume. Vale transcrever então o art. $6^{\circ} \mathrm{da}$ LINDB: “Art. $6^{\circ} \mathrm{A}$ Lei em vigor terá efeito imediato e geral, respeitados o ato jurídico perfeito, o direito adquirido e a coisa julgada”.

Sabedor da necessidade de composição de eventuais dificuldades de interpretação, quando se houvessem iniciado prazos sob a égide da lei anterior, que tenham sofrido alterações com a nova lei, o art. 2.028 do CC/02 traz regra de direito intertemporal, para os prazos prescricionais e decadenciais já em curso, e que houverem sido alterados pela lei nova.

Assim, segundo o dispositivo, se os prazos prescricionais forem reduzidos pela lei nova - o que deveras ocorreu na maioria dos casos - resta ao intérprete saber quanto desse prazo já decorreu. Vale transcrever o texto legal: "Art. 2.028. Serão os da lei anterior os prazos, quando reduzidos por este Código, e se, na data de sua entrada em vigor, já houver transcorrido mais da metade do tempo estabelecido na lei revogada."

Duas interpretações surgiram a esse respeito. A alternativa ou disjuntiva, que entende que duas seriam as hipóteses de aplicação dos prazos da lei antiga: a) quando reduzidos pelo $\mathrm{CC} / 02$; ou b) quando transcorrido mais da metade de seu prazo quando da entrada em vigor do CC/02. A outra interpretação, conjuntiva, exige a presença de ambos os requisitos, ou seja, que: a) o prazo tenha sido reduzido; e b) que já tenha transcorrido mais da metade com a entrada em vigor do CC/02.
A CLT trouxe regra de direito intertemporal mais simples, em seu art. 916, a saber: "Art. 916 - Os prazos de prescrição fixados pela presente Consolidação começarão a correr da data da vigência desta, quando menores do que os previstos pela legislação anterior".

Retornando a atenção ao CC, nota-se que decorrido mais da metade do prazo sob a égide da lei anterior, tendo tal prazo sido reduzido pela lei nova, observa-se o prazo antigo. Tendo-se reduzido o prazo pela lei nova, mas ainda não decorrido metade desse prazo sob a égide da lei antiga, aplica-se o prazo da lei nova.

É a interpretação conjuntiva que tem merecido aplausos da doutrina, sendo preferida pelo enunciado 50 da I Jornada do Conselho da Justiça Federal.

Segundo Maria Helena Diniz (2003), a lei nova deu eficácia à antiga quanto ao tempo anterior, impondo-lhe certos limites. 0 art. 2.028 do CC/02 apresenta uma postura prático-normativa ao estabelecer uma continuidade entre o momento passado e o presente, estabelecendo regras para o cômputo do tempo para a configuração da prescrição e da decadência.

Ressalte-se, todavia, que a interpretação prevalente parece ferir o princípio da isonomia, privilegiando o antigo credor que se mostra inerte, e prejudicando o novo credor, que não terá muito tempo para exercer seu direito.

Entretanto, entendimento oposto seria alcançado, ao se levar em conta que o espírito do CC/02 foi exatamente o de reduzir os prazos prescricionais, prezando assim, pela celeridade de composição das controvérsias jurídicas.

Em relação ao caso concreto em análise, admitindo-se, hipoteticamente, que a negativa do plano de saúde tenha ocorrido em 01.01.2000, cabe indagar se o prazo prescricional anterior foi reduzido pelo $\mathrm{CC} / 02$ e se, na data de sua entrada em vigência (11.01.2003) já tinha transcorrido mais da metade daquele prazo. 
Ora, se não se pode aplicar o art. 27 do $C D C$ para pretensão decorrente de responsabilidade contratual, o único prazo possível era o geral de 20 anos, previsto no art. 177 do CC/16.

Trata-se então de um prazo de 20 anos do CC/16, reduzido para 10 anos no $\mathrm{CC} / 02$.

No entanto, ainda não teria transcorrido mais da metade do prazo vintenário, reduzido para decenal.

Essa situação não preenche, portanto, os requisitos cumulativos do art. 2.028 do CC/02, ou seja, de redução do prazo na lei nova e de transcurso de mais da metade do prazo antigo.

Desta feita, o prazo a ser aplicado é o geral, de 10 anos, do art. 205 do CC/02.

\subsection{INTERRUPÇÃO DA CONTAGEM DO PRAZO PRESCRICIONAL}

No caso em análise não se operou a prescrição, porque houve a interrupção da contagem do prazo de prescrição.

Para facilitar o estudo da interrupção da prescrição faz-se necessário compará-la com os institutos da suspensão e do impedimento da prescrição.

O impedimento e a suspensão da prescrição são fatos jurídicos que sobrestam o andamento do prazo, devido à impossibilidade ou à inoportunidade de se alegar a prescrição em determinado tempo ou durante a verificação de determinada situação jurídica.

0 que diferencia o impedimento da suspensão é apenas o início da contagem do prazo. Se o prazo já havia começado a escoar e sobreveio um evento taxativamente previsto em lei, o prazo será suspenso, retomando seu curso de onde parou, ou seja, aproveitando-se o tempo já transcorrido, após cessada aquela situação jurídica. Já no impedimento, o prazo
Por força do princípio da irretroatividade da norma, previsto no art. $6^{\circ}$ da LINDB, a contagem do prazo do CC/02 não pode retroagir para alcançar momento anterior a sua vigência.

Assim, a contagem do decênio tem por base a data de 11.01.2003 (data de vigência do CC/02). Seu art. 132 determina que computam-se os prazos, excluído o dia do começo, e incluído o do vencimento. Portanto, o início do prazo prescricional é 12.01 .2003 e seu término é 11.01.2013.

Para exercer sua pretensão ressarcitória, o autor deveria ter proposto a ação condenatória até 11.01.2013.

ainda não havia se iniciado quando da verificação de determinada situação jurídica, caso em que somente terá seu início quando finda aquela situação.

A interrupção, por sua vez, faz com que o prazo já iniciado seja desprezado, reiniciando a contagem novamente. Ou seja, a presença de uma causa interruptiva faz zerar a contagem.

Distingue-se da suspensão/impedimento, porque enquanto esta é automática, advinda de fatos jurídicos aos quais a lei atribui tais efeitos, a interrupção pressupõe, em regra, ato do credor incompatível com sua inércia. 0 elenco taxativo das causas interruptivas da prescrição vem previsto no art. 202 do CC, interessando ao caso seu inc. I, nos termos seguintes:

Art. 202. A interrupção da prescrição, que somente poderá ocorrer uma vez, dar-se-á:

I - por despacho do juiz, mesmo incompetente, que ordenar a citação, se o interessado a promover no prazo e na forma da lei processual; [...] 
Parágrafo único. A prescrição interrompida recomeça a correr da data do ato que a interrompeu, ou do último ato do processo para a interromper.

No caso em análise, a prescrição foi interrompida com a propositura da ação (que ocorreu em
16.05.2008) e sua contagem só recomeçou, do zero, quando da publicação do julgamento do REsp. 1.176.320/RS, no Diário de Justiça eletrônico de 26.02.2013.

\section{CONCLUSÕES}

O estudo da prescrição é tema sempre presente na ordem do dia. Sua complexidade não atinge apenas aos alunos de graduação ou de pós-graduação, mas também aos operadores do direito e membros da magistratura, como se pôde demonstrar na divergência de interpretação dos arts. 205 e 206, § 30, V, do CC, entre as instâncias ordinárias do TJ/RS e o STJ.

Não obstante os 10 anos de vigência do CC/02, constatou-se que a importância da regra de direito in- tertemporal do art. 2.028 faz-se sentir não só no plano teórico doutrinário, mas também na prática forense.

Com esses pontos polêmicos e atuais tratados nas linhas que se seguiram, acredita-se que o tema da prescrição, se tratado de modo simples, claro e objetivo nas salas de aula, tanto de graduação como de pós-graduação, poderá despertar a simpatia do aluno, ao invés de angustiá-lo com o receio de não o compreender.

\section{REFERÊNCIAS}

AMARAL, Francisco. Direito civil: introdução. 5. ed. Rio de Janeiro: Renovar, 2005.

AZEVEDO, Álvaro Villaça. Teoria geral das obrigações. 10. ed. São Paulo: Atlas, 2004.

BETTI, Emilio. Teoria geral do negócio jurídico. Tradução de Ricardo Rodrigues Gama. Campinas: LZN, 2003. t. 3.

CARBONIER, Jean. Droit civil. Paris: Presses Universitaires de France, 1956. t. 2.

COMPARATO, Fábio Konder. A afirmação histórica dos direitos humanos. 7. ed. São Paulo: Saraiva, 2010.

CRETELA JÚNIOR, José. Direito romano moderno: introdução ao direito civil brasileiro. 7. ed. Rio de Janeiro: Forense, 1998.

DINIZ, Maria Helena. Comentários ao Código Civil. V. 22. São Paulo: Saraiva, 2003.

FRANCESCHELLI, Vincenzo. Diritto privato. 3. ed., v. 2. Milano: Giuffrè, 2007. 
GABURRI, Fernando. Direito civil para sala de aula. Curitiba: Juruá, 2012.

GOMES, Orlando. Introdução ao direito civil. 13. ed. Rio de Janeiro: Forense, 1998.

VASCONCELOS, Pedro Pais de. Teoria geral do direito civil. 4. ed. Coimbra: Almedina, 2007.

Recebido em: 22 de fevereiro de 2013

Avaliado em: 3 de março de 2013

Aceito em: 8 de março de 2013
1 Mestre em Direito Civil Comparado pela PUC/SP e doutorando em Direitos Humanos pela USP. Professor Assistente de direito civil da Universidade do Estado do Rio Grande do Norte - UERN e do Centro Universitário do Rio Grande do Norte - Uni-RN. Professor do curso de pós-graduação em Direito Civil e Processual Civil da Universidade Tiradentes - UNIT. Procurador do Município do Natal/RN e advogado. Diretor Nacional do Núcleo de Estudos dos Direitos da Pessoa com Deficiência do Instituto Brasileiro de Advocacia Pública - IBAP. E-mail: gaburri@terra.com.br. 